\title{
Prevalence and Risk Factors of Infectious Spondylodiscitis in Benin's Children
}

\author{
Zavier Zomalheto ${ }^{*}$, Michee Assogba2 ${ }^{2}$, Vanessa Zannou ${ }^{1}$ \\ ${ }^{1}$ Rheumatology Unit of National Hospital, University Hubert Koutoukou Maga of Cotonou, Cotonou, Benin \\ ${ }^{2}$ Paediatric Unit of National Hospital, University Hubert Koutoukou Maga of Cotonou Maga de Cotonou, Cotonou, Benin \\ Email: *zozaher@yahoo.fr
}

How to cite this paper: Zomalheto, Z., Assogba, M. and Zannou, V. (2018) Prevalence and Risk Factors of Infectious Spondylodiscitis in Benin's Children. Open Journal of Rheumatology and Autoimmune Diseases, 8, 71-78.

https://doi.org/10.4236/ojra.2018.82007

Received: March 6, 2018

Accepted: May 22, 2018

Published: May 25, 2018

Copyright $\odot 2018$ by authors and Scientific Research Publishing Inc. This work is licensed under the Creative Commons Attribution International License (CC BY 4.0).

http://creativecommons.org/licenses/by/4.0/

\begin{abstract}
Aim: To determine the prevalence and risk factor of infectious spondylodiscitis in children in Benin. Patients and Method: A descriptive cross-sectional study over 5 years was conducted in rheumatology and paediatric departments of National Hospital University Hubert Koutoukou Maga of Cotonou among children suffered from osteoarticular disorders. We selected patients with infectious spondylodyscitis. The data collected were analyzed using SPSS 20.0 software. Results: Among 179 children treated for osteo-articular disorders, 29 (16.2\%) had infectious spondylodiscitis. There were 11 girls and 18 boys (sex ratio $=1.55)$. The main symptoms were dominated by low back pain (72.4). Fever was present in $58.6 \%$ of patients. Laboratory parameters of inflammation were higher than normal in all of the patients. Paraparesia was present in one case. L2-L3 disc was most affected (45.2\% of cases). Mycobacterium tuberculosis was incriminated in $75,8 \%$. Common places germs were dominated by negative baccillus germs (62.5\%). The treatment was medical with a minimum duration of 3 months. All patients were immobilized with a lumbostat over a period of 3 months. Sicle cells disease, HIV, no BCG vaccination were the risk factors identified respectively in 9.4\%, $11.3 \%$ and $16 \%$. Conclusion: Diagnosis of spondylodiscitis in children is difficult in our country Keeping in mind unspecific subjective complaints and clinical findings. Early diagnosis uses magnetic resonance imaging which cost high and remains beyond the reach of our patients. Therefore, effective antibiotic therapy should be started promptly as soon as the diagnosis is suspected to avoid serious complications.
\end{abstract}

\section{Keywords}

Spondylodiscitis, Children, Benin

\section{Introduction}

Spondylodiscitis is a rare disorder which is easily missed. It presents with 
non-specific symptoms such as irritability, abdominal pain, decreased appetite and limping. The infection parameters can be normal, and blood cultures are often negative. Diagnostic golden standard is magnetic resonance imaging. The treatment is immobilization, anti-inflammatory drugs and often antibiotics. Early treatment is important to reduce the risk of complications such as nerve damage and spine fusion [1].

In children, infectious spondylodiscitis, the simultaneous infection of a vertebral disc and the adjacent vertebral bodies, are rare diseases that can cause significant clinical problems [2]-[7]. Moreover, when the infection spreads into the spinal channel, it can cause devastating neurologic complications.

In the time before the use of antibiotics, mortality due to pyogenic spondylodiscitis reached $90 \%$ [8]. Currently, due to better diagnostic tools and improvements in medical and surgical treatment, mortality is significantly reduced and is lower than $5 \%$. However, in a not insignificant number of cases, spondylodiscitis can lead to serious spinal deformities and segmental instabilities. These severe complications are quite common in non-pyogenic infections, including cases due to Mycobacterium tuberculosis that are endemic in some developing and emerging countries but are diagnosed also in the industrialized world [2] [3] [4] [5] [6]. Early diagnosis and treatment might reduce these risks [9] [10]. Non-specific spondylodiscitis in children is caused by haematogenous spread of pathogens. Staphylococcus aureus is the most frequently detected bacterium. The clinical signs are unspecific and an Magnetic Resonance Imaging of the spine is the standard radiological procedure to detect spondylodiscitis. In general, the treatment is conservative and includes an antibiotic therapy as well an immobilization of the spine. In endemic areas of the world, specific spondylodiscitis is more common and is caused by Mycobacterium tuberculosis or Brucellae. The treatment is also conservative. For all entities of spondylodiscitis in children, a surgical intervention is only necessary in the case of severe deformities due to the infection or in the case of neurological symptoms [10] [11].

The condition has an incidence of $2 \%$ to $4 \%$ of all infectious skeletal diseases in children in industrialized countries [12] [13]. In Benin as the majority of the one of less developping country in Africa, prevalence of spondylodiscitis is well know in adult (reached to 4.3\%) but unknown in the children [14] [15]. The aim of this work was to determine the prevalence and risk factors of infectious spondylodiscitis in Benin children.

\section{Patients and Method}

This was a cross-sectional and descriptive study from January 2012 to December 2017 on children followed in rheumatology and paediatric departments of $\mathrm{Na}$ tional Hospital University Hubert Koutoukou Maga of Cotonou among children who met the following criteria:

- Be under 18 years old

- Have consulted in one of the 2 departments during the study period

- Have suffered from infectious spondylodiscitis 
The diagnosis of infectious spondylodiscitis was established by a combination of clinical history, physical examination, results of the tests of inflammatory markers, radiological assessment, and MRI if available

Children with another form of spondylodiscitis were not included in the study.

Comprehensive recrutement of children fulfilling the inclusion criteria has been achieved. Data was analyzed using SPSS 18.0 software.

\section{Results}

\subsection{Sociodemographic Data}

Among 179 children treated for osteo-articular disorders, 29 (16.2\%) had infectious spondylodiscitis. There were 11 girls and 18 boys (sex ratio $=1.55$ ).

The teenagers' group was the most represented age group (65.5\%) followed by grade schooler (24.1\%) and the toddlers (10.4\%)

\subsection{Clinical Features}

The mean delay of consultation was $45 \pm 9$ [7-90] days.

The main symptoms were dominated by low back pain (72.4). Neurological complications were present in $7 \%$ of cases. All patients had various systemic symptoms but fever was present in 58.6\%. Table 1 and Table 2 summarized the clinical features.

\subsection{Paraclinical Data}

L2-L3 disc was most affected (45.2\% of cases) followed by L3-L4 disc (19.35\%) and imaging was normal in $11.5 \%$ of children.

Laboratory parameters of inflammation were higher than normal in all of the patients.

Mycobacterium tuberculosis was incriminated in 21 (72.4\%) cases.

Common places germs were identified in 6 cases et were dominated by negative baccillus germs (62.5\%) and summarized in Figure 1.

\subsection{Treatment and Risk Factors}

The treatment was medical dominated by antibiotics for 3 months and antituberculosis drugs for 12 months.

All patients were immobilized with a lumbostat over a period of 3 months.

Sicle cells disease, HIV, no BCG vaccination were the risk factors identified respectively in $10.3 \%, 13.8 \%$ and $6.9 \%$. Table 3 shows the risk factors of spondylodiscitis in our children

\section{Discussion}

Infectious Spondylodiscitis is less frequent in children than eldery in our country [14] [16]. Indeed, spondylodiscitis in children is rare. The condition has an incidence of $2 \%$ to $4 \%$ of all infectious skeletal diseases in children [12]. Our 
Table 1. Delay for consultation.

\begin{tabular}{ccc}
\hline Time (in days) & number $(\mathbf{n}=\mathbf{1 7 9})$ & Percentage $(\%)$ \\
\hline$<30$ & 11 & 37.9 \\
$30-90$ & 17 & 58.7 \\
$>90$ & 1 & 3.4 \\
\hline
\end{tabular}

Table 2. Clinical manifestations.

\begin{tabular}{ccc}
\hline & Number & $\%$ \\
\hline Rachialgia & & \\
Lumbar spine & 21 & 72.4 \\
Thoracic spine & 08 & 27.6 \\
Cervical spine & 0 & 0 \\
Kyphosis & 9 & 31 \\
Stiffness & 29 & 100 \\
Neurologic manifestations & & \\
sciatic pain & 8 & 27.6 \\
paraparesia & 1 & 3.4 \\
Systemic symptoms & & \\
Fever & 17 & 58.6 \\
Weight loss & 21 & 72.4 \\
Anorexia & 12 & 41.3 \\
\hline
\end{tabular}

Table 3. Risk factors of the children.

\begin{tabular}{ccc}
\hline & Number & $\%$ \\
\hline Sicle cells disease & 3 & 10.3 \\
HIV & 4 & 13.8 \\
No BCG & 2 & 6.9 \\
No factors identified & 20 & 69 \\
\hline
\end{tabular}

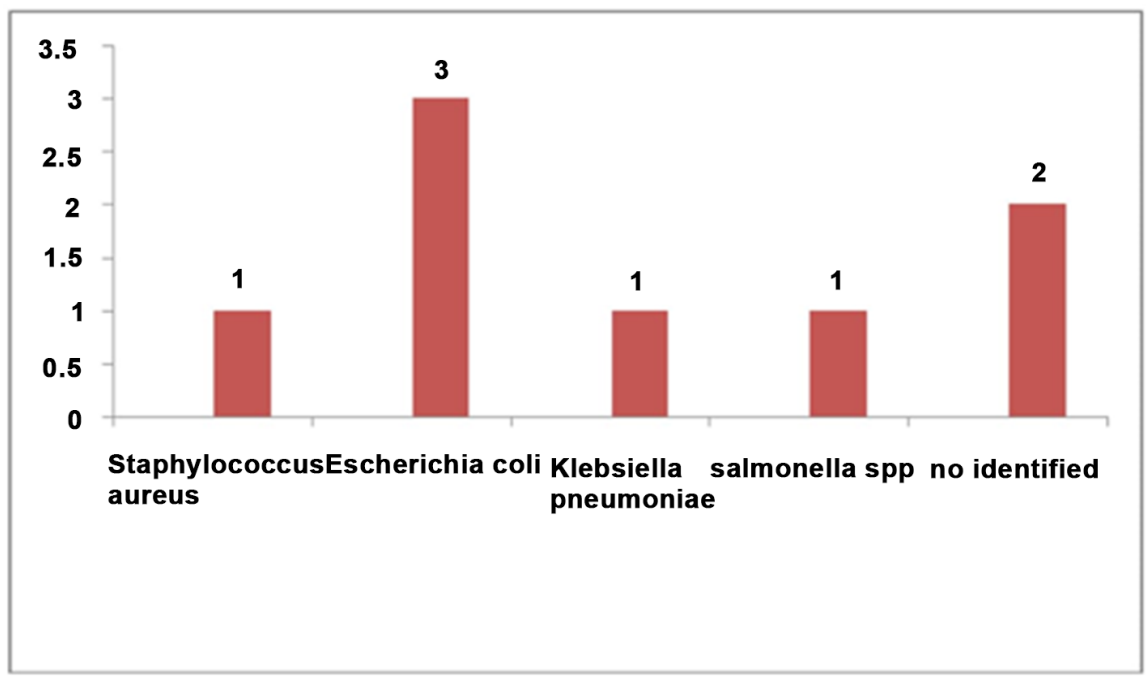

Figure 1. Common places germs. 
high hospital frequency can be explain by the presence of more risk factors (31\%).

The clinical manifestations were dominated by low back pain (72.4), stiffness and one systemic symptoms were seen in all of the children. Neurological complications were seen in $31 \%$.

Clinical manifestations of infectious spondylodiscitis can significantly vary [2] [17] [18]. Cases occurring in neonates or younger infants are usually the most severe and are frequently associated with sepsis and multiple infectious foci. The vertebrae can be severely damaged and sometimes entirely destroyed, leading to kyphosis.

In toddlers and preschool-aged children, signs and symptoms of disease are frequently mild. Most patients have low-grade fever, and only a minority exhibit significant neurologic manifestations. Neurological complications were seen in $31 \%$ in our series and paparesia in $3.1 \%$ of cases. Theses complications in our chidren is higher than those seen in Garon et al. Series who described $10 \%$ of chidren who presented neurologic signs and once case of paraplegia [2]. Kayser et al. described reduced general conditions which were in their study with refusal, reduced ability, or inability to walk or sit in $24 \%$ [2] [9].

Rahialgia was always combined with stiffness. Similar data were reported by kayse et al. [2] [18]. Therfore,in children, early clinical manifestations are non specific, the diagnosis of spondylodyscitis frequently cannot be established until relatively late in the course of the disease. In our seies, the mean delay of consultation was more than 6 weeks. Delays of $4-6$ months have been described by several authors [2] [17] [18]

Finally, in older children and teenagers, the clinical picture resembling that evidenced in the elderly [9] [18].

Benin is one of the endemic countries of tuberculosis in Africa, that explain the higher prevalence of this germ among our children. The majority of diagnosis was made using clinical et radicological signs combinated with the positivity of intradermal reaction to tuberculin. It seems rare in children in industrilized country [2]. Diagnosis of spondylodiscitis due to tuberculosis is difficult and delay may lead to the rapid progression of disease [19] [20].

For common places germs, diagnosis is often based on Positive blood cultures and sampling at infectious sites [10] [21].

Concerning the antibiotic, in the management of our children, we use 3 months for common places germs and 12 months for tuberculosis such as recommends in most countries [9]

In accordance with the national Tuberculosis control program in Benin, all patients received chemotherapy for 12 months, including two months of quadruple therapy (rifampicin, isoniazid, pyrazinamide and ethambutol), followed by 10 months of treatment with rifampicin and isoniazid. Spinal immobilization, in a corset, was indicated for all patients for 3 months.

For common places germs, the situation is some confusing since there is no 
agreement in the literature regarding the antibiotics' ability to enter discs in an active form. In fact, the antibiotic's ability to spread through all parts of the disc is not only influenced by the vascular supply and structure of the disc (size and health), but also

by the properties of the drug (size, solubility, binding and charge) [22] [23] [24]. The antibiotic's charge in particular has been discussed in the literature, since the nucleus pulposus is rich in glycosaminoglycans and has a high density of negative charge [24]. Thus, it has been postulated that positively charged antibiotics (gentamicin or vancomycin) can enter the IVD, whereas negatively charged antibiotics (penicillin and cephalosporins) have limited [25] [26] [27] or poor penetration [28] because of repellent charges. The length and route of treatment depend above all on the pathogen's virulence, as well as the clinical and laboratory response to treatment (decreases of pain, fever, CRP, and ESR). In our children, we use two antibiotics choose between both cephalosporin 3rd generation fluoroquinolone, gentamicin and lincomycin for the treatment of common places germs.

\section{Conclusion}

Diagnosis of spondylodiscitis in children is difficult in our country Keeping in mind unspecific subjective complaints and clinical findings. Early diagnosis uses magnetic resonance imaging which cost high and remains beyond the reach of our patients. Therefore, effective antibiotic therapy should be started promptly as soon as the diagnosis is suspected to avoid serious complications.

\section{References}

[1] Benhassen, L.L., Balslev, T., Gammelgaard, L., Kristensen, L.H. and Møller-Madsen, B. (2016) Intervertebral Discitis in Children. Ugeskr Laeger, 178, 1156-1162.

[2] Cushing, A.H. (1993) Diskitis in Children. Clinical Infectious Diseases, 17, 1-6. https://doi.org/10.1093/clinids/17.1.1

[3] Fernandez, M., Carrol, C.L. and Baker, C.J. (2000) Discitis and Vertebral Osteomyelitis in Children: An 18-Year Review. Pediatrics, 105, 1299-1304. https://doi.org/10.1542/peds.105.6.1299

[4] Kayser, R., Mahlfeld, K., Greulich, M. and Grasshoff, H. (2005) Spondylodiscitis in Childhood: Results of a Long-Term Study. Spine, 30, 318-323. https://doi.org/10.1097/01.brs.0000152097.57891.98

[5] Cottle, L. and Riordan, T. (2008) Infectious Spondylodiscitis. J. Infect.. 56, 401-412. https://doi.org/10.1016/j.jinf.2008.02.005

[6] Cornett, C.A., Vincent, S.A., Crow, J. and Hewlett, A. (2016) Bacterial Spine Infections in Adults: Evaluation and Management. Journal of the American Academy of Orthopaedic Surgeons, 24, 11-18. https://doi.org/10.5435/JAAOS-D-13-00102

[7] Ceroni, D., Kampouroglou, G., Valaikaite, R., Anderson della Llana, R. and Salvo, D. (2014) Osteoarticular Infections in Young Children: What Has Changed over the Last Years? Swiss Medical Weekly, 144, w13971. https://doi.org/10.4414/smw.2014.13971 
[8] Ferroni, A., Al Khoury, H., Dana, C., Quesne, G., Berche, P., Glorion, C. and Péjin, Z. (2013) Prospective Survey of Acute Osteoarticular Infections in a French Paediatric Orthopedic Surgery Unit. Clinical Microbiology and Infection, 19, 822-828. https://doi.org/10.1111/clm.12031

[9] Principi, N. and Esposito, S. (2016) Infectious Discitis and Spondylodiscitis in Children. International Journal of Molecular Sciences, 17, 539.

https://doi.org/10.3390/ijms17040539

[10] Völker, A., Schubert, S. and Heyde, C.E. (2016) Spondylodiscitis in Children and Adolescents. Rthopade, 45, 491-499. https://doi.org/10.1007/s00132-016-3273-6

[11] Soares do Brito, J., Tirado, A. and Fernandes, P. (2016) Surgical Treated Spondylodiscitis: Epidemiological Study. Acta Medica Portuguesa, 29, 319-325. https://doi.org/10.20344/amp.6549

[12] Scheuerman, O., Landau, D., Schwarz, M., Hoffer, V., Marcus, N., Hoffnung, L.A. et al. (2015) Cervical Discitis in Children. The Pediatric Infectious Disease Journal, 34, 794-795. https://doi.org/10.1097/INF.0000000000000725

[13] Mitha, A., Boutry, N., Nectoux, E., Petyt, C., Lagree, M., Happiette, L., et al. (2015) Network for Evaluating the Management of Infectious Diseases in Children, 2014. Community-Acquired Bone and Joint Infections in Children: A 1-Year Prospective Epidemiological Study. Archives of Disease in Childhood, 100, 126-129. https://doi.org/10.1136/archdischild-2013-305860

[14] Zomalheto, Z., Avimadje, M., Gounongbe, M. and Dossou-Yovo, H. (2010) Risk Factors of Tuberculosis Discitis in Benin. Le Bénin medical, 44, 30-32.

[15] Ekere, A., Yellowé, B. and Echem, R. (2005) Conservative Management of Tuberculos Spondylitis in Developing Country. Nigeria Journal of Medicine, 14, 386-389.

[16] Zomalheto, Z., Kobelembi, A., Agbodande, A., Dossou-Yovo, H., Zossoungbo, F. and Avimadje, M. (2015) Epidemio-Clinical, Paraclinical and Therapeutic Profile of Infectious Spondylodiscitis in Hospital Consultation at Cotonou. Medecine d Afrique Noire, 62, 405-410.

[17] Kapsalaki, E., Gatselis, N., Stefos, A., Makaritsis, K., Vassiou, A., Fezoulidis, I. and Dalekos, G.N. (2009) Spontaneous Spondylodiscitis: Presentation, Risk Factors, Diagnosis, Management, and Outcome. International Journal of Infectious Diseases, 13, 564-569. https://doi.org/10.1016/j.ijid.2008.08.025

[18] Jain, A.K., Sreenivasan, R., Mukunth, R. and Dhammi, I.K. (2014) Tubercular Spondylitis in Children. Indian Journal of Orthopaedics, 48, 136-144. https://doi.org/10.4103/0019-5413.128747

[19] Trecarichi, E.M., Di Meco, E., Mazzotta, V. and Fantoni, M. (2012) Tuberculous Spondylodiscitis: Epidemiology, Clinical Features, Treatment, and Outcome. European Review for Medical and Pharmacological Sciences, 16, 58-72.

[20] Eisen, S., Honywood, L., Shingadia, D. and Novelli, V. (2012) Spinal Tuberculosis in Children. Archives of Disease in Childhood, 97, 724-729.

https://doi.org/10.1136/archdischild-2011-301571

[21] Chandrasenan, J., Klezl, Z., Bommireddy, R. and Calthorpe, D. (2011) Spondylodiscitis in Children: A Retrospective Series. The Journal of Bone and Joint Surgery. British Volume, 93, 1122-1125. https://doi.org/10.1302/0301-620X.93B8.25588

[22] Azbaoui, S., Alaoui Mrani, N., Sabri, A., Jouhadi, Z., Ailal, F., Bousfiha, A.A., et al. (2015) Pott's Disease in Moroccan Children: Clinical Features and Investigation of the IL-12/IFN- $\gamma$ Pathway. International Journal of Tuberculosis and Lung Disease, 19, 1455-1462. https://doi.org/10.5588/ijtld.15.0290 
[23] Benzagmout, M., Boujraf, S., Chakour, K. and Chaoui Mel, F. (2011) Pott's Disease in Children. Surgical Neurology International, 2, 1. https://doi.org/10.4103/2152-7806.75459

[24] Dulani, R., Shrivastava, S. and Singh, P. (2010) A Rare Case Report: Tubercular Spondylodiscitis Following Lumbar Disc Surgery. Asian Pacific Journal of Tropical Medicine, 3, 496-498. https://doi.org/10.1016/S1995-7645(10)60120-4

[25] Boscardin, J.B., Ringus, J.C., Feingold, D.J. and Ruda, S.C. (1992) Human Intradiscal Levels with Cefazolin. Spine, 17, S145-S148. https://doi.org/10.1097/00007632-199206001-00014

[26] Fraser, R.D., Osti, O.L. and Vernon-Roberts, B. (1989) Iatrogenic Discitis: The Role of Intravenous Antibiotics in Prevention and Treatment. An Experimental Study. Spine, 14, 1025-1032. https://doi.org/10.1097/00007632-198909000-00018

[27] Rhoten, R.L., Murphy, M.A., Kalfas, I.H., Hahn, J.F. and Washington, J.A. (1995) Antibiotic Penetration into Cervical Discs. Neurosurgery, 37, 418-421. https://doi.org/10.1227/00006123-199509000-00008

[28] Riley, L.H., Banovac, K., Martinez, O.V. and Eismont, F.J. (1994) Tissue Distribution of Antibiotics in the Intervertebral Disc. Spine, 19, 2619-2625. 